\section{Endoscopic Factors that Can Predict Histological Ulcerations in Early Gastric Cancers}

\author{
Jaesin Lee', Byung-Wook Kim', Cheal Wung Huh', Joon Sung Kim and Lee-So Maeng ${ }^{2}$ \\ Department of ${ }^{1}$ Internal Medicine, ${ }^{2}$ Pathology, Incheon St. Mary's Hospital, College of Medicine, The Catholic University of Korea, Incheon, \\ Korea
}

Background/Aims: Predicting histological ulceration in early gastric cancer (EGC) during endoscopic examination is crucial for endoscopists deciding on the treatment modality. The aim of this study was to investigate the endoscopic factors that can predict histological ulcerations in EGCs.

Methods: We retrospectively analyzed patients who underwent endoscopic submucosal dissection (ESD) for EGC. Clinical features and endoscopic characteristics of EGC such as location, histological differentiation, longest diameter, tumor morphology, mucosal break, converging fold, color change, and surface irregularity were reviewed. Histological ulceration was defined based on ESD specimens. Results: A total of 633 EGC lesions from 613 patients were included and histological ulcerations were found in 90 lesions (14.2\%). Presence of converging folds, tumor morphology, and color changes on endoscopic examination were related to histological ulceration in the univariate analysis and converging folds along with color changes were statistically significant factors in the multivariate analysis. Kaplan-Meier analysis showed that patients with histological ulcerations in EGCs tended to have higher marginal recurrence rates. Conclusions: Mucosal breaks are not equivalent to histological ulcerations. Rather, the existence of converging folds and color changes during endoscopic examination suggest histological ulcerations. Endoscopists should consider these factors when they decide the treatment modality for EGCs. Clin Endosc 2020;53:328-333

Key Words: Early gastric cancer; Endoscopic submucosal dissection; Ulceration

\section{INTRODUCTION}

Endoscopic submucosal dissection (ESD) has become one of the major treatment modalities in early gastric cancer (EGC) for the last few decades. ${ }^{1}$ EGCs with elevated lesions less than $2 \mathrm{~cm}$ in diameter and differentiated mucosal cancer without ulcerations are suggested as absolute indications for endoscopic resection. ${ }^{2}$ However, many endoscopists attempted

Received: July 3, 2019 Revised: July 29, 2019

Accepted: August 4, 2019

Correspondence: Byung-Wook Kim

Department of Internal Medicine, Incheon St. Mary's Hospital, College of Medicine, The Catholic University of Korea, 56 Dongsu-ro, Bupyeong-gu, Incheon 21431, Korea

Tel: +82-32-280-5052, Fax: +82-32-280-5987, E-mail: gastro@catholic.ac.kr ORCID: https://orcid.org/0000-0002-2290-4954

(cc) This is an Open Access article distributed under the terms of the Creative Commons Attribution Non-Commercial License (http://creativecommons.org/ licenses/by-nc/3.0) which permits unrestricted non-commercial use, distribution, and reproduction in any medium, provided the original work is properly cited. to overcome the restrictive criteria and have now expanded them to include: (1) well or moderately differentiated adenocarcinomas without an ulcer, regardless of size; (2) well or moderately differentiated adenocarcinomas measuring less than $3 \mathrm{~cm}$ with ulcers; (3) small intramucosal cancers with undifferentiated histology; and (4) well or moderately differentiated adenocarcinomas with minute submucosal invasions. These criteria were adopted by the Japanese and Korean gastric cancer treatment guidelines. ${ }^{3,4}$

To avoid unnecessary procedures, endoscopists should cautiously select patients who meet the criteria for ESD. The size of the lesions can be measured during endoscopic examinations, and histological differentiation is confirmed after endoscopic biopsy. However, the presence of histological ulcerations may be difficult to determine before ESD. The presence of ulceration in EGC is closely related to the depth of invasion and lymphovascular invasion. ${ }^{2}$

We previously reported that most endoscopists tend to con- 
sider mucosal breaks in EGCs as ulcerations. ${ }^{5}$ However, determining the presence of ulcerations based on mucosal breaks may lead to overestimation of lesions and lead to unnecessary surgery. Moreover, ulcerations in EGCs may heal and mucosal breaks may not exist during endoscopic examination, resulting in unnecessary endoscopic procedures. Therefore, determining the presence of histological ulcerations is crucial in deciding the treatment modality. To the best of our knowledge, endoscopic factors that can predict histological ulcerations in EGCs have not been investigated so far, and thus, the aim of this study was to investigate these factors.

\section{MATERIALS AND METHODS}

\section{Patients}

We retrospectively reviewed patients who underwent ESD for EGC from May 2002 to January 2017 at Incheon St. Mary's Hospital, The Catholic University of Korea. Patients diagnosed with non-epithelial tumors, carcinomas other than adenocarcinomas, and gastric adenomas were excluded. Patient follow-up lasted until the cut-off date of October 31, 2018. Patients were divided into 2 groups according to the presence or absence of histological ulcerations after ESD. Demographic features such as age and sex were analyzed and compared be- tween the groups. This study was approved by the Institutional Review Boards of The Catholic University of Korea.

\section{Histologic evaluation}

Four gastrointestinal pathologists reviewed the whole specimen according to the Vienna Classification. ${ }^{6}$ Histological ulceration was defined as follows; mucosal defect involving the submucosa, deformity of the muscularis propria, or fibrosis in the submucosal or deeper layer. ${ }^{2}$ Masson's trichrome staining was performed to evaluate fibrosis of the submucosal or deeper layer. Differentiated tumors were categorized into 2 groups: differentiated tumor including well or moderately differentiated adenocarcinomas and undifferentiated tumor including poorly differentiated adenocarcinomas or signet ring cell carcinoma, according to the Japanese classification of gastric carcinoma. ${ }^{7}$ Depth of invasion and the ESD criteria were evaluated based on the pathology report, according to the Korean guidelines for gastric cancer. ${ }^{4}$

\section{Endoscopic factors}

Two endoscopists (JL and BWK) reviewed and analyzed the endoscopic images obtained before ESD and discussed with each other until a conclusion was reached. At least 3 endoscopic images from different angles for EGCs were reviewed and analyzed. Endoscopic characteristics of EGCs such as

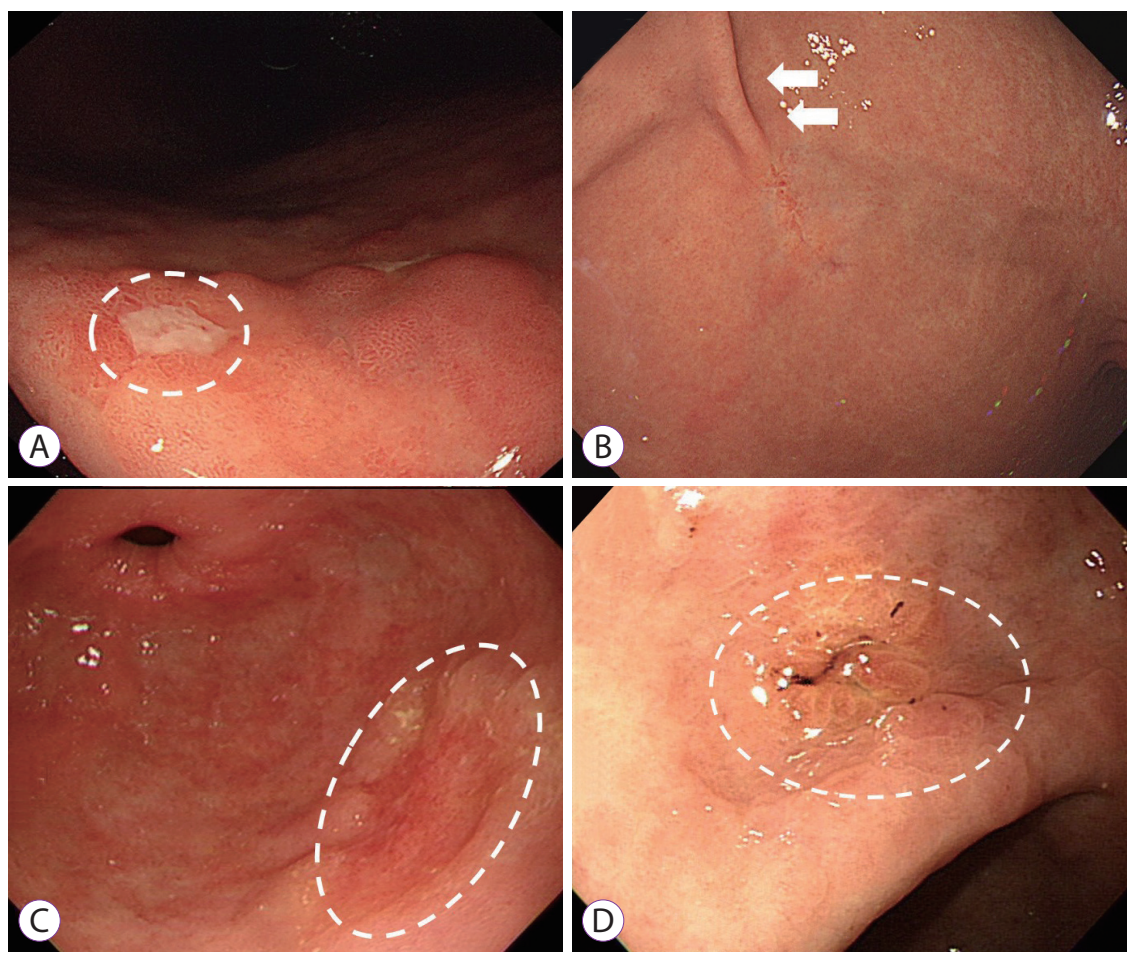

Fig. 1. Representative images of endoscopic factors associated with histological ulcerations. (A) Mucosal break (white-dotted circle); (B) Converging fold (white arrows); (C) Color change (white-dotted circle); (D) Irregular surface (white-dotted circle). 
tumor location, tumor size, tumor morphologies, mucosal breaks, converging folds, color changes, and surface irregularities were compared between the groups. Tumor location was classified into 3 parts based on the longitudinal axis of the stomach: upper, middle, or lower third. Tumor size was defined as the longest diameter measured with biopsy forceps during endoscopic examination. Tumor morphology was classified into 4 types according to the Paris classification ${ }^{8}$ : elevated (Paris classification O-I, O-IIa), flat (Paris classification O-IIb), depressed (Paris classification O-IIc, O-III), or mixed. The presence of any mucosal defects regardless of the depth of invasion was regarded as the presence of a mucosal break. Converging folds were indicated by the presence of any centripetal folds in the EGC lesions. Color changes were indicated by discoloration in any part of the lesion or in the whole lesion in contrast to the color of the surrounding mucosa. The representative endoscopic appearance of each morphological characteristic is depicted in Fig. 1. The cumulative recurrence rate and long-term survival were compared between the groups.

\section{Statistical analysis}

Demographic features and endoscopic factors were compared between the groups according to the presence of histological ulcerations using the $\chi$-squared tests or independent $t$-tests. A logistic regression analysis was performed to clarify the independent endoscopic factors that predict histological ulcerations in EGCs. The Kaplan-Meier method was used to determine the cumulative recurrence rate, and a log-rank test was used to analyze differences in the recurrence curve. A $p$-value less than 0.05 was considered statistically significant. Statistical analysis was performed using SPSS version 20.0 (SPSS Inc., Chicago, IL, USA).

\section{RESULTS}

\section{Clinicopathological features}

Baseline characteristics are presented in Table 1. A total of 633 EGC lesions from 613 patients were included and histological ulcerations were found in 90 lesions (14.2\%). There was

Table 1. Baseline Characteristics of 633 Lesions from 613 Patients

\begin{tabular}{|c|c|c|c|c|}
\hline Characteristics & $\begin{array}{c}\text { Total } \\
(n=633)\end{array}$ & $\begin{array}{l}\text { Histological ulceration }(+) \\
\qquad(n=90)\end{array}$ & $\begin{array}{l}\text { Histological ulceration (-) } \\
\qquad(n=543)\end{array}$ & $p$-value \\
\hline Sex ${ }^{a)}$ & & & & 0.449 \\
\hline Male & $434(68.6 \%)$ & $64(73.6 \%)$ & $370(70.3 \%)$ & \\
\hline Female & $179(31.4 \%)$ & $23(26.4 \%)$ & $156(29.7 \%)$ & \\
\hline Mean age $^{\mathrm{a})}(\mathrm{yr}, \pm \mathrm{SD})$ & $65.2 \pm 9.5$ & $64.7 \pm 9.4$ & $65.3 \pm 9.5$ & 0.541 \\
\hline Tumor location & & & & 0.791 \\
\hline Upper & $30(4.7 \%)$ & $4(4.4 \%)$ & $26(4.8 \%)$ & \\
\hline Middle & $219(34.6 \%)$ & $34(37.8 \%)$ & $185(34.1 \%)$ & \\
\hline Lower & $384(60.7 \%)$ & $52(57.8 \%)$ & $332(61.1 \%)$ & \\
\hline Tumor size $^{\mathrm{b})}(\mathrm{mm})$ & & & & 0.416 \\
\hline$\leq 10$ & $207(32.7 \%)$ & $29(32.2 \%)$ & $178(32.8 \%)$ & \\
\hline $11-20$ & $247(39.0 \%)$ & $40(44.4 \%)$ & $207(38.1 \%)$ & \\
\hline $21-30$ & $107(16.9 \%)$ & $15(16.7 \%)$ & $92(16.9 \%)$ & \\
\hline$\geq 31$ & $72(11.4 \%)$ & $6(6.7 \%)$ & $66(12.1 \%)$ & \\
\hline Differentiation & & & & 0.552 \\
\hline Differentiated & $587(92.7 \%)$ & $82(91.1 \%)$ & $505(93.0 \%)$ & \\
\hline Undifferentiated & $46(7.3 \%)$ & $8(8.9 \%)$ & $38(7.0 \%)$ & \\
\hline Depth of invasion & & & & 0.483 \\
\hline Mucosa & $545(86.1 \%)$ & $76(84.4 \%)$ & $469(86.4 \%)$ & \\
\hline $\mathrm{sm} 1$ & $39(6.2 \%)$ & $8(8.9 \%)$ & $31(5.7 \%)$ & \\
\hline $\mathrm{sm} 2$ & $49(7.7 \%)$ & $6(6.7 \%)$ & $43(7.9 \%)$ & \\
\hline
\end{tabular}

$\mathrm{SD}$, standard deviation.

${ }^{a)}$ Sex ratio and mean age were calculated from 613 patients and others were calculated from 633 lesions.

b) Tumor size was defined as the longest diameter of the early gastric cancer. 
no difference in sex ratio, mean age, location of tumors, tumor size, and differentiation of tumors between the groups.

\section{Endoscopic factors}

We compared 6 endoscopic factors (longest diameter, tumor morphologies, mucosal breaks, converging folds, color changes, and surface irregularities) between the groups. Among them, tumor morphologies, converging folds, and color changes were statistically significant in the univariate analysis ( $p=0.013, p=0.001$, and $p=0.008$, respectively; Table 2 ). In the multivariate analysis, converging folds (odds ratio [OR], 2.27; 95\% confidence interval [CI], 1.24-4.09; $p=0.005)$ and color changes (OR, 2.33; 95\% CI, 1.14-4.76; $p=0.020$ ) were independent factors predicting histological ulcerations (Table 2).

\section{Long-term outcomes of endoscopic submucosal dissection in patients with and without ulcerations}

The mean follow-up duration was 66.4 months (range, 21-196 months) for all patients; 39.9 months (range, 21-88 months) in patients with histological ulcerations, and 61.0 months (range, 21-196 months) in patients without histological ulcerations. There was no difference in recurrence rate between patients with or without histological ulcerations $(13.3 \%$ vs. $12.9 \%, p=0.401)$. In the subgroup analysis, there was no dif- ference in metachronous recurrence rate between the groups (7.8\% vs. $10.1 \%, p=0.974$ ). Although not statistical significant, the marginal recurrence rate tended to be somewhat higher in patients with ulcerations than that in patients without $(5.6 \%$ vs. $2.8 \%, p=0.080$; Fig. 2 ).

\section{DISCUSSION}

In this study, we found that converging folds and color changes of EGCs on endoscopic examination were closely related to histological ulcerations. Most endoscopists intuitively judge that EGC lesions have ulcers when they observe mucosal breaks in the lesions. ${ }^{5}$ Furthermore, inter-observer variability for the presence of endoscopic ulcerations in EGCs was reported. ${ }^{9}$ Even endoscopic ultrasound cannot exactly predict the existence of histological ulcerations in EGCs. ${ }^{10,11}$ Considering that the classic and expanded criteria for ESD were based on histology after surgical resection, ${ }^{2}$ these endoscopic factors suggest the existence of histological ulcerations more accurately before surgical or endoscopic resection.

Ulcerations in EGCs may be healed without any medical treatment. Moreover, the healing process in EGCs is quite similar to that seen in benign ulcers. ${ }^{12,13}$ Surface irregularities

Table 2. Endoscopic Factors that Can Predict Histological Ulcerations

\begin{tabular}{|c|c|c|c|c|}
\hline \multirow{2}{*}{ Endoscopic factors } & \multirow{2}{*}{$\begin{array}{l}\text { Histological ulceration }(+) \\
\qquad(n=90)\end{array}$} & \multirow{2}{*}{$\begin{array}{l}\text { Histological ulceration }(-) \\
\qquad(n=543)\end{array}$} & \multicolumn{2}{|c|}{$p$-value } \\
\hline & & & Univariate analysis & Multivariate analysis \\
\hline Tumor morphology & & & 0.013 & 0.054 \\
\hline Elevated & $13(14.4 \%)$ & $149(27.4 \%)$ & & \\
\hline Flat & $25(27.8 \%)$ & $165(30.4 \%)$ & & \\
\hline Depressed & $27(30.0 \%)$ & $136(25.0 \%)$ & & \\
\hline Mixed & $25(27.8 \%)$ & $93(17.1 \%)$ & & \\
\hline Mucosal breaks & & & 0.549 & - \\
\hline Yes & $44(48.9 \%)$ & $247(45.5 \%)$ & & \\
\hline No & $46(51.1 \%)$ & $296(54.5 \%)$ & & \\
\hline Converging folds & & & 0.001 & $0.005^{\mathrm{a})}$ \\
\hline Yes & $22(24.4 \%)$ & $63(11.6 \%)$ & & \\
\hline No & $68(75.6 \%)$ & $480(88.4 \%)$ & & \\
\hline Color changes & & & 0.008 & $0.020^{\mathrm{b})}$ \\
\hline Yes & $80(88.9 \%)$ & 415 (76.4\%) & & \\
\hline No & $10(11.1 \%)$ & $128(23.6 \%)$ & & \\
\hline Surface irregularity & & & 0.054 & - \\
\hline Yes & $45(50.0 \%)$ & $213(39.2 \%)$ & & \\
\hline No & $45(50.0 \%)$ & $330(60.8 \%)$ & & \\
\hline
\end{tabular}

a) Odds ratio, 2.27; 95\% confidence interval, 1.27-4.05.

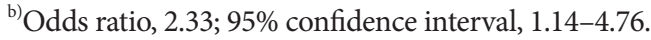


were observed during the healing process of mixed type EGCs in a previous study. ${ }^{12}$ In our study, surface irregularities tended to correlate with the presence of histological ulcerations although this result was not statistically significant. Converging folds in EGCs may originate from previous ulcerations during the healing process and suggest the existence of histological ulcerations. However, endoscopists encounter EGCs in any stage and converging folds without mucosal breaks may be observed despite histological ulcerations. Endoscopists should carefully examine EGCs for the presence of any converging folds near the lesions.

Discoloration of the mucosa in EGCs usually results from the changing vascularity within the carcinomatous mucosa. ${ }^{14}$ In addition, previous reports showed that the discoloration of mucosa was more commonly found in undifferentiated than in differentiated EGCs. ${ }^{15,16}$ However, there have been no reports on the relationship between mucosal discoloration and histological ulcerations in EGCs. It is plausible that scar stages in EGCs with ulceration present discoloration like in benign ulcers.

Mucosal breaks do not indicate ulcerations. In this study,
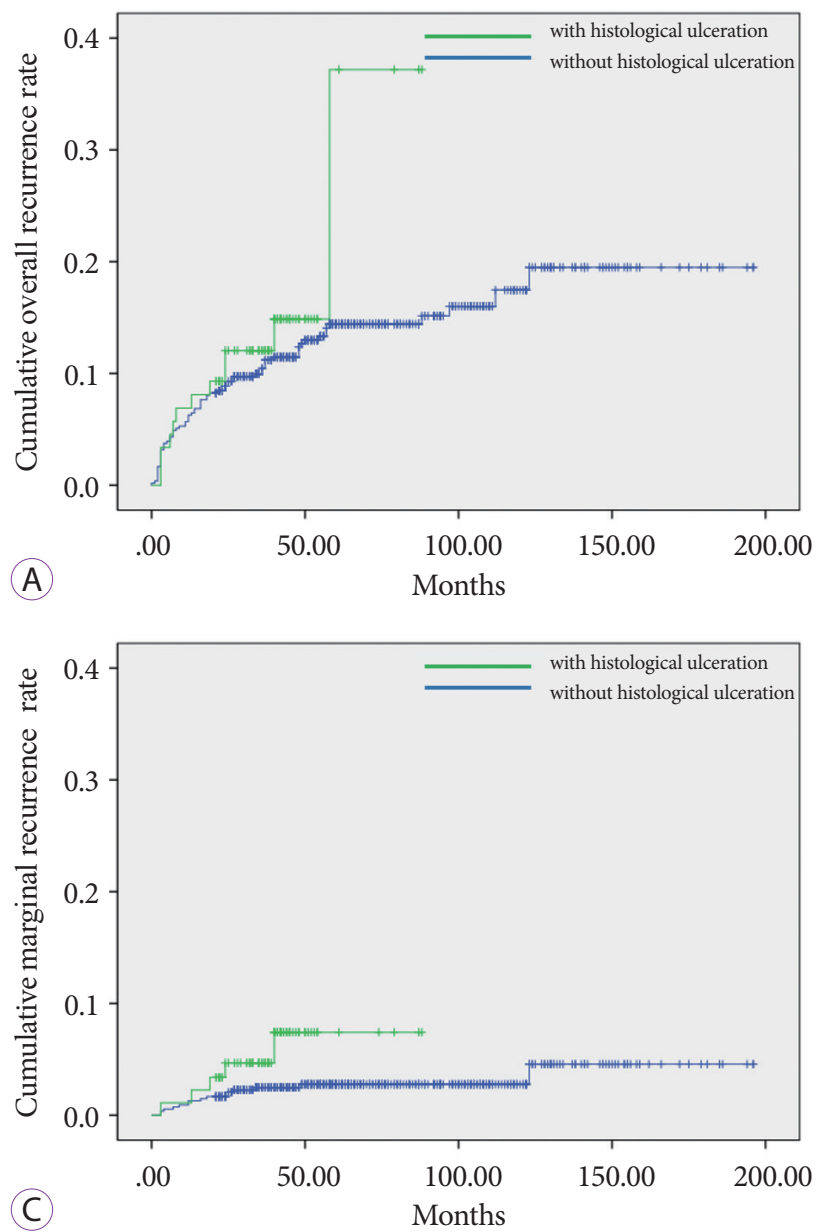

only half of the patients with mucosal breaks showed histological ulcerations. Considering that even experienced endoscopists sometimes consider erosive lesions in EGCs as ulcerations," the term "mucosal break" is preferred than "endoscopic ulcer" as in the current study. Endoscopists should be careful when they describe ulcerations in EGCs, and they should limit the use of the term "endoscopic ulcer" to only when the mucosal defect penetrates the submucosal layer. Other minor endoscopic findings should also be carefully examined.

Although, it was not statistically significant, the incidence of marginal recurrence rates was higher in patients with histological ulcers in EGCs than in those without. To identify the correlation between histological ulcers and marginal recurrence in EGCs, a large prospective study should be conducted in the future.

There are some limitations in this study. First, this study had a retrospective design and was conducted at a single center; thus, selection bias may exist. Second, this study included ESD cases and did not include surgical specimens. Third, the interval between diagnostic biopsy and ESD was not assessed due to limited data. We could not obtain the biopsy date when

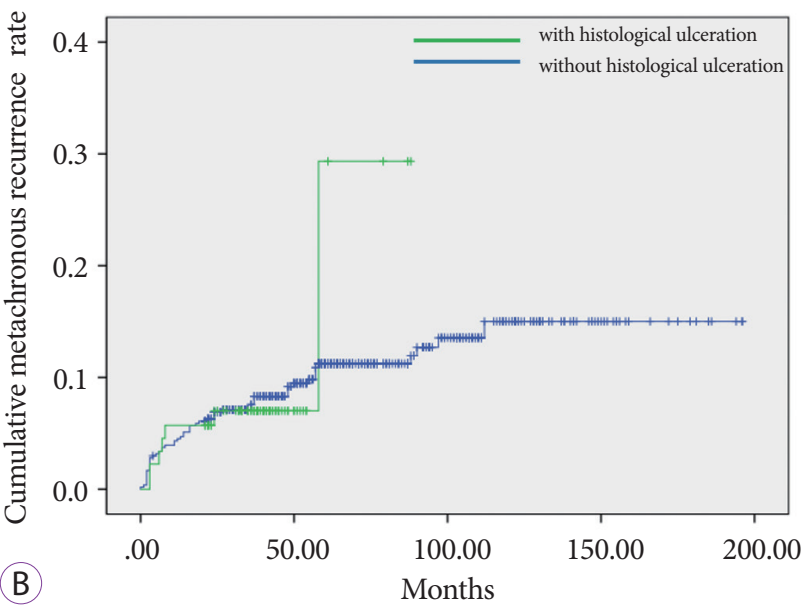

Fig. 2. Recurrence rates. (A) Overall recurrence $(n=82, p=0.401)$; (B) Metachronous recurrence ( $n=62, p=0.974)$; (C) Marginal recurrence $(n=20, p=0.080)$. 
the diagnostic endoscopy was not performed in our hospital. Fourth, the size of the mucosal break was not measured accurately due to the retrospective design.

In conclusion, mucosal breaks are not equivalent to histological ulcerations. The existence of converging folds and color changes in EGCs during endoscopic examination suggest histological ulcerations. Endoscopists should consider these endoscopic factors when deciding the treatment modality for EGCs.

Conflicts of Interest

The authors have no financial conflicts of interest.

\section{ORCID}

Jaesin Lee: https://orcid.org/0000-0001-8981-0445

Cheal Wung Huh: https://orcid.org/0000-0001-7327-8503

Joon Sung Kim: https://orcid.org/0000-0001-9158-1012

Lee-So Maeng: https://orcid.org/0000-0003-0512-315X

\section{REFERENCES}

1. Chung IK, Lee JH, Lee SH, et al. Therapeutic outcomes in 1000 cases of endoscopic submucosal dissection for early gastric neoplasms: Korean ESD Study Group multicenter study. Gastrointest Endosc 2009;69:12281235.

2. Gotoda T, Yanagisawa A, Sasako M, et al. Incidence of lymph node metastasis from early gastric cancer: estimation with a large number of cases at two large centers. Gastric Cancer 2000;3:219-225.

3. Japanese Gastric Cancer Association. Japanese gastric cancer treatment guidelines. 5th ed. Tokyo: Kanehara-Shuppan; 2018.
4. Lee JH, Kim JG, Jung HK, et al. Clinical practice guidelines for gastric cancer in Korea: an evidence-based approach. J Gastric Cancer 2014; 14:87-104

5. Park SM, Kim BW, Kim JS, Kim YW, Kim GJ, Ryu SJ. Can endoscopic ulcerations in early gastric cancer be clearly defined before endoscopic resection? A survey among endoscopists. Clin Endosc 2017;50:473-478.

6. Schlemper RJ, Riddell RH, Kato Y, et al. The Vienna classification of gastrointestinal epithelial neoplasia. Gut 2000;47:251-255.

7. Japanese Gastric Cancer Association. Japanese gastric cancer treatment guidelines 2014 (ver. 4). Gastric Cancer 2017;20:1-19.

8. The Paris endoscopic classification of superficial neoplastic lesions: esophagus, stomach, and colon: November 30 to December 1, 2002. Gastrointest Endosc 2003;58(6 Suppl):S3-S43.

9. Kwee RM, Kwee TC. Predicting lymph node status in early gastric cancer. Gastric Cancer 2008;11:134-148.

10. Park JS, Kim H, Bang B, Kwon K, Shin Y. Accuracy of endoscopic ultrasonography for diagnosing ulcerative early gastric cancers. Medicine (Baltimore) 2016;95:e3955.

11. Akashi K, Yanai H, Nishikawa J, et al. Ulcerous change decreases the accuracy of endoscopic ultrasonography diagnosis for the invasive depth of early gastric cancer. Int J Gastrointest Cancer 2006;37:133-138.

12. Sakita T, Oguro Y, Takasu S, Fukutomi H, Miwa T. Observations on the healing of ulcerations in early gastric cancer. The life cycle of the malignant ulcer. Gastroenterology 1971;60:835-839 passim.

13. Lee JI, Kim JH, Kim JH, et al. Indication for endoscopic treatment of ulcerative early gastric cancer according to depth of ulcer and morphological change. J Gastroenterol Hepatol 2012;27:1718-1725.

14. Honmyo U, Misumi A, Murakami A, et al. Mechanisms producing color change in flat early gastric cancers. Endoscopy 1997;29:366-371.

15. Yao K, Yao T, Matsui T, Iwashita A, Oishi T. Hemoglobin content in intramucosal gastric carcinoma as a marker of histologic differentiation: a clinical application of quantitative electronic endoscopy. Gastrointest Endosc 2000;52:241-245.

16. Lee HH, Lee SY, Yoon HY, et al. Change of mucosal color in early gastric cancer. J Dig Dis 2012;13:510-516. 